\title{
Determinants of efficiency in residential electricity demand: stochastic frontier analysis on Japan
}

Akihiro Otsuka

\begin{abstract}
Background: Rapidly increasing residential electricity demand has made raising energy efficiency an important policy issue in controlling electricity demand.

Methods: This study uses a stochastic frontier model to estimate the residential electricity demand function and analyse electricity energy efficiency levels and their determinants using regional data on Japan.

Results: The results confirm the importance of household dwelling types for determining the electricity energy efficiency. Specifically, the findings suggest that household size and floor area are key to electricity savings, but the ageing Japanese society shows a limited relationship with electricity savings. Further, promoting living in areas where the population has aggregated also results in electricity savings.

Conclusions: The findings suggest that forming urbanised cities and realising multi-polarisation-type national spatial developments might improve electricity energy efficiency and stimulate regional economies.
\end{abstract}

Keywords: Energy efficiency, Stochastic frontier analysis, Electricity, Household, Dwelling, Japan

\section{Background}

Residential energy consumption in Japan is influenced by changes in social structure, such as the lifestyles of individuals pursuing greater convenience and comfort in their lives, and also by the number of households, which has increased significantly alongside the growth in individual consumption. In Japan, energy consumption in the residential sector in 1973 was set as 100 and, by 2011, this value had risen to 208.9, indicating energy consumption had grown to more than twice its value at the time of the first oil shock. Therefore, increasing energy conservation in the residential sector has become a pressing issue, and the Japanese government has implemented a variety of measures to achieve it [1].

Up to around 1965, roughly the start of Japan's period of high economic growth, coal constituted more than one third of residential energy consumption. Subsequently, it was replaced by kerosene, and by 1973, coal constituted only around $6 \%$ of residential energy

Correspondence: otsuka@yokohama-cu.ac.jp

Association of International Arts and Science, Yokohama City University, 22-2, Seto, Kanazawa-ku, Yokohama 236-0027, Japan consumption. At that point, kerosene, electric power, and gas (city gas and liquefied petroleum gas) each accounted for one third of energy consumption, but subsequently, electric power's share increased significantly due to the spread of new consumer electronic devices that grew in size and functionality. Recently, all-electric homes have become widespread, and in 2011, electric power's share reached $50.6 \%$, a figure that suggests the importance of analysing electricity demand for residential use.

Japanese energy consumption is mainly affected by energy intensity (energy consumption per capita) [2]. However, energy intensity is not a suitable index of energy efficiency [3-5], because it depends upon a variety of socioeconomic factors that do not affect energy efficiency. Therefore, many researchers have attempted to develop and use other efficiency indexes to measure energy efficiency. Recently, efficiency index measurements have used stochastic frontier analysis (SFA) and data envelopment analysis (DEA) using data from various countries [6-9]. Nonetheless, most previous research focused only on efficiency index scores and did not fully analyse their 
determinants. To address this literature gap, this study not only measures the levels of efficiency, but also analyses their determinants.

Otsuka [2] analyses the efficiency of residential energy demand in Japan, focusing on population agglomeration and electrification rates as determinants of residential energy efficiency, and shows that residential energy efficiency is high in population agglomeration areas. This study focuses on residential electricity demand as an extension of his research, mainly because household electricity is consumed the most in urban areas where population agglomerates. In Japan, around $70 \%$ of the population lives in urban areas, where there are many multi-dwelling houses, such as condominiums. Furthermore, electrification in urban areas is progressing significantly compared to rural ones. Such urban area concentrations may thus lead to efficient energy use. Otsuka's research reveals that residential energy is consumed efficiently in urban areas [2]. This study further analyses this consideration from the viewpoint of housing characteristics: (1) household size (members), (2) housing floor area, and (3) ageing, and clarifies how these affect the efficiency of residential electricity demand. First, it measures efficiency scores based on the SFA method and, second, analyses the impact of household dwelling types on efficiency scores to clarify the importance of household characteristics for electricity efficiency. Finally, this study evaluates whether promoting living in population aggregated areas results in electricity savings. Within the growth strategies for regional economies in Japan, the importance of forming urbanised cities has been advocated for both economic and environmental aspects. As such, it is necessary to verify whether an urbanised city policy that targets the transition from decentralised cities to urbanised (centralised) cities is effective for energy and electricity conservation in Japan's regions.

The remainder of the paper is organised as follows. The "Literature review" section reviews previous research on energy efficiency, focusing on SFA studies, and the "Methods" section presents the framework for empirical analysis and describes the model and data. The "Results and discussion" section presents the results of the empirical analysis, and the "Conclusions" section provides the conclusion and policy implications of the study.

\section{Literature review}

To estimate energy efficiency levels, it is possible to use both parametric and non-parametric frontier approaches [6-9]. The parametric approach, such as SFA, is based on an econometric model. In the non-parametric approach, such as DEA, the frontier function is a decision function of several variables.
SFA assumes a specific function type for the efficiency frontier and estimates the efficiency frontier parametrically. The basic idea in SFA is first estimating the efficiency frontier and, based on this estimation, measuring the efficiency by calculating the relative distances from the actual data points to the frontier. As this method has a high discrimination capability regarding the evaluation of energy efficiency values, it has been used by numerous researchers to measure energy efficiency levels in an entire country and in specific industries. For instance, a merit of SFA is that particularly high observed efficiency values (abnormal values) are obtained compared to other samples and the stochastic production frontier can absorb a significant part of the impact of these abnormal values, symmetrically, in the error term. Therefore, the problem of the instability of energy demand function estimates due to abnormal values in view of high efficiency can be avoided. Therefore, this study uses the SFA approach. Specifically, the electricity demand data used in this study are official processing data and may have statistical noise, which can be handled by SFA but is not possible to process if DEA was used. As the DEA method does not normally consider statistical errors, it also does not consider errors in the efficiency frontier specification. In other words, it does not allow the introduction of all explanatory variables into the estimation formula, thus not considering the errors that occur from the absence of various elements. Additionally, for a sample with particularly high observed efficiency values (abnormal values) compared to other samples, in DEA, the efficiency frontier is determined to include these observed values as a technically completely efficient sample, since a negative deviation from the frontier is not allowed. Consequently, result reliability may be greatly impaired. Zhou et al. [9] describe an SFA approach to estimate economy-wide energy efficiency performance from a production efficiency viewpoint and find that the proposed parametric frontier (SFA) approach has greater discriminating power in energy efficiency performance measurements than its nonparametric frontier (e.g. DEA) counterparts.

Since the SFA method has a strong analytical capability for assessing the energy efficiency score, it has been used by numerous researchers to measure energy efficiency levels. For example, Feijoo et al. [10] measured the energy efficiency of industries in Spain and concluded that energy policy and regulation reduced $\mathrm{CO}_{2}$ emissions. Buck and Young [11] gauged the energy efficiency of commercial buildings in Canada and established that such commercial buildings are highly energy efficient and that building ownership and economic activities are the main determinants of energy efficiency. Boyd [12] analysed the energy efficiency of wet corn milling plants and argued that the advantage of using 
SFA to measure energy efficiency is the possibility of avoiding issues regarding the definition of energy intensity. Boyd et al. [13] used SFA to estimate plant-level energy efficiency for the manufacturing sector in the USA, while Aranda-Uson et al. [14] analysed the energy efficiency and measured the energy efficiency scores of four industries-food, drink, and tobacco manufacturing, textiles, chemicals, and non-metallic mineral products-in Spain. Their results show that the total energy consumption of these four industries could be reduced by about 20\%. Filippini and Hunt [15] measured the energy efficiency of 29 Organisation for Economic Co-operation and Development countries between 1978 and 2006, and they [16] also assessed the energy consumption and efficiency of the residential sector in the USA using statelevel data between 1995 and 2007. Lin and Yang [17] measured the energy efficiency of the thermal power industry in China, while Lin and Wang [18] measured the energy efficiency of the iron and steel industry in China. Filippini and Zhang [19] estimated energy efficiency in Chinese provinces and showed it improved in China's various industries and provinces.

Many previous studies that used SFA focused on measuring energy efficiency levels. Therefore, while such studies have measured the energy efficiency levels of various countries, regions, and industries, only Lin and Wang [18] have empirically analysed the determinants of energy efficiency levels. ${ }^{1}$

Recently, the focus shifted to urban structures that concentrate the population in a specific region (urbanised cities), and some studies indicated that an urban structure with high population density may cause increased energy efficiencies.

Newman and Kenworthy [20] were the first to examine such a relationship between energy efficiency and urban structures. Using data from 32 cities across the world in 1980, they looked at population density as a scale of urban structure and found a negative relationship between population density and per-capita gasoline consumption. Bento and Cropper [21], using data from 114 US cities for 1990, examined whether urban structures and public transportation influence the choice of transportation for commuting and car mileage at household level. They demonstrated that the probability of driving to work decreases when population centrality and rail miles are higher and road density is lower. They also showed that population centrality, job-housing balance, city shape, and road density have significant effects on annual household vehicle miles travelled, thus increasing energy consumption. Brownstine and Golob [22], using data for the state of California, analysed the relationships between residential density, private vehicle usage, and private vehicle fuel consumption, demonstrating that population density has a direct effect on vehicle usage, and that both private vehicle usage and population density affect fuel consumption. Karathodorou et al. [23] used cross-sectional data from 84 cities worldwide to show how population density affects the demand for automobile fuel. Additionally, they estimated the elasticity of fuel demand relative to population density, concluding that the propensity to walk or ride a bicycle increases in high-density cities because transportation distances are shorter and that per-capita fuel consumption decreases because public transportation can substitute the use of private vehicles. Su [24] demonstrated how urban structures affect household gasoline consumption across 50 cities in the USA. Considering traffic congestion and highway density as part of the urban structure, $\mathrm{Su}$ showed that population density negatively affects household gasoline consumption. Morikawa [25] and Otsuka and Goto [26, 27] examined the effect of population density on energy efficiency and demonstrated that energy efficiency improved when the population density increased.

Compared to regions where the population is dispersed, residential living in multi-dwelling housing, such as condominiums, is advancing in regions where population is agglomerating. Compared to detached housing, it is highly likely that energy use in multi-dwelling housing is more efficient, mostly because floor area is smaller and living areas have better heat insulation and highly efficient cooling and heating systems. Therefore, it is assumed that energy consumption wastage will be reduced. Moreover, in multi-dwelling housing, there could be more opportunities to share electricity use between household members. All these factors will ultimately improve energy efficiency.

This study focuses on the relationship between urban residence types and energy efficiency. Specifically, focusing on electricity demand, which accounts for most residential energy demand, this study examines the relationships between household dwelling types and the efficiency of residential electricity demand.

\section{Methods \\ Empirical model}

The residential electricity demand function F (Eq. 1) is assumed to hold at the prefectural level:

$\mathrm{ED}_{j t}=\mathrm{F}\left(\mathrm{P}_{j t}, \mathrm{IC}_{j t}, \mathrm{HS}_{j t}, \mathrm{FA}_{j t}, \mathrm{AG}_{j t}, \mathrm{CDD}_{j t}, \mathrm{HDD}_{j t}, \mathrm{EF}_{j t}\right)$,

where $\mathrm{ED}_{j t}$ is the residential electricity demand per household for the $j$ th $(j=1, \ldots, J)$ prefecture in the th period, $\mathrm{P}$ residential sector's real electricity price, IC the real household income, HS household size, FA household floor area, AG population ageing rate, CDD cooling degree day (element of temperature), and HDD heating 
degree day (element of temperature). Unfortunately, since the electricity efficiency level (EF) cannot normally be directly observed in economic systems, it is necessary to estimate it. In this study, electricity efficiency levels are estimated using the stochastic frontier demand approach proposed by Filippini and Hunt $[8,15,16]$. As described in the literature review, the parametric frontier (SFA) approach has many advantages over the nonparametric frontier (DEA) approach. Therefore, this study applies energy-based SFA to a dataset at the Japanese prefectural level.

SFA was originally proposed by Meeusen and van den Broeck [28], Aigner et al. [29], and Battese and Corra [30]. Various types of SFA models were also proposed by other researchers for measuring economic activity efficiency. A comprehensive survey, along with a variety of advanced SFA models, can be found in the work of Kumbhakar and Lovell [31].

The SFA model can investigate the level of regionspecific efficiency. Furthermore, this study provides a linkage between the SFA-based efficiency measure and regional components to identify energy efficiency determinants. Such a methodological feature is important because this study uses a panel dataset with a time series aspect for each prefecture. It is commonly known that the energy efficiency measure, as investigated in this study, requires decomposition into several factors that explain energy efficiency improvement. Thus, the SFA approach is useful in dealing with a panel dataset. Moreover, we can handle unobserved heterogeneity by using a panel dataset.

Among the proposed SFA models, this study applies the model of Battese and Coelli [32], because it can examine the mean inefficiency of firms by a single-stage regression, using various explanatory variables for efficiency. Following the traditional method, we usually apply a two-stage approach to estimate efficiency and its relationship with determinants. The single-stage regression method of Battese and Coelli [32] can solve an inconsistency issue remaining in the two-stage approach that is caused by an assumption about the independence of inefficiency. ${ }^{2}$
Regarding the proposed methodology, this study uses an energy demand frontier model, which can be specified in a logarithmic form (Eq. 2):

$$
\begin{gathered}
\text { 1n } \mathrm{ED}_{j t}=\alpha+\alpha_{\mathrm{P}} 1 \mathrm{n} \mathrm{P}_{j t}+\alpha_{\mathrm{IC}} 1 \mathrm{n} 1 \mathrm{IC}_{j t}+\alpha_{\mathrm{HS}} 1 \mathrm{n} \\
\mathrm{HS}_{j t}+\alpha_{\mathrm{FA}} 1 \mathrm{n} \mathrm{FA}_{j t}+\alpha_{\mathrm{AG}} \mathrm{n} \mathrm{AG}_{j t} \\
+\alpha_{\mathrm{CDD}} 1 \mathrm{n} \mathrm{CDD}_{j t}+\alpha_{\mathrm{HDD}} 1 \mathrm{n} \mathrm{HDD}_{j t}+v_{j t}+u_{j t} .
\end{gathered}
$$

The symbol $\alpha$ represents parameter estimates and indicates a constant parameter $\left(\alpha_{0}\right)$, while the other parameters represent the level of energy demand $\left(\alpha_{i}, i=\mathrm{P}\right.$, IC, HS, FA, AG, CDD, HDD). The error term $v_{j t}+u_{j t}$ consists of two parts: an observational error term $\left(v_{j t}\right)$ and the inefficiency-related error term $\left(u_{j t}\right)$. The error term $v_{j t}$ is assumed to be i.i.d. $N\left(0, \sigma_{v}^{2}\right)$, as well as independent from the inefficiency-related error term $u_{j t}$ and all regressors of the proposed energy demand production. The term $u_{j t}$ is a non-negative random variable, assumed to be independently distributed as the truncation at zero of the $N\left(\mu, \sigma_{u}^{2}\right)$ distribution. The term $u_{j t}$ expresses the efficiency of electricity level EF in (1), interpreted as the index of inefficiency (wasted electricity consumption).

Given Eq. (2), the estimated level of energy efficiency $\mathrm{EF}_{j t}$ is estimated using the conditional mean of the efficiency term $E\left(u_{j t} \mid v_{j t}+u_{j t}\right)$ proposed by Jondrow et al. [33]. The level of energy efficiency $\mathrm{EF}_{j t}$ is measured by the ratio of observed energy demand $E_{j t}$ to the estimated energy demand frontier $E_{j t}^{F}[8]$. That is,

$$
\mathrm{EF}_{j t}=E_{j t}^{F} / E_{j t}=e^{-u_{j t}}, \quad 0<\mathrm{EF}_{j t} \leq 1 .
$$

This study formulates mean energy efficiency $\mu_{j t}$ as follows:

$$
\begin{aligned}
\mu_{j t}= & \beta_{0}+\beta_{\mathrm{HS}} 1 \mathrm{nHS}_{j t}+\beta_{\mathrm{FA}} 1 \mathrm{nFA}_{j t} \\
& +\beta_{\mathrm{AG}} 1 \mathrm{nAG}_{j t},
\end{aligned}
$$

\begin{tabular}{|c|c|c|c|c|c|}
\hline Description & Variable & Mean & Std. dev. & Maximum & Minimum \\
\hline Electricity demand $\left(10^{6} \mathrm{kWh}\right)$ & ED & 5315 & 5265 & 32,871 & 895 \\
\hline Real electricity rate $(2005=100)$ & $P$ & 107.86 & 7.93 & 136.17 & 94.75 \\
\hline Household real income (JPY, millions) & IC & 6.81 & 1.26 & 10.16 & 4.04 \\
\hline Household size (person) & $\mathrm{HS}$ & 2.82 & 0.32 & 3.69 & 2.00 \\
\hline Household floor area $\left(\mathrm{m}^{2}\right)$ & FA & 101.16 & 19.54 & 152.90 & 56.81 \\
\hline Ageing population ratio (\%) & $A G$ & 19.11 & 4.21 & 28.96 & 8.45 \\
\hline Cooling-degree day & CDD & 366 & 175 & 1186 & 0 \\
\hline Heating-degree day & HDD & 1107 & 470 & 2769 & 0 \\
\hline
\end{tabular}

In the event of an efficiency improvement, the sign of $\beta$ will be negative. In this study, an improvement of energy efficiency is thus explained through multiple considerations, because such improvement occurs through not

Table 1 Descriptive statistics 
only the technological and organisational determinants of energy demand, but also socioeconomic ones in the production and consumption of energy services. First, it is assumed that energy efficiency increases with household size, because more residents share lighting and other electricity uses in kitchens. A household uses electricity and appliances for many tasks, such as to a warm meal. Therefore, electricity and appliances are partially used as inputs in the production of a warm meal [34]. As household sizes increases, their members share home appliances, and hence, electricity demand per household member improves, increasing electricity use efficiency. Therefore, the coefficients of household size (HS) can take negative signs. Second, it is also assumed that there is energy waste in decentralised cities. Otsuka [2] finds low energy efficiency in Japan's non-metropolitan regions, which contain many decentralised cities with numerous detached houses. As detached houses in decentralised cities tend to have large floor areas per household membership, it is therefore anticipated that the larger the floor area (FA), the lower electricity efficiency is. That is, the FA coefficient values are expected to be positive. Third, ageing (AG) can take negative values because the elderly are less active and are sensitive to electricity savings compared to younger people.

\section{Data}

This study's dataset consists of data from Japan's 47 prefectures from 1990 to 2010. Since there are many types of regional energy statistics, we compiled the dataset from various sources. ${ }^{3}$ Prefectural residential electricity demand data is from the Energy Consumption Statistics by Prefecture (Agency for Natural Resources and Energy, the Ministry of Economy, Trade and Industry). For the relative price index, electricity rates from the consumer price index are used for each prefectural capital, deflated by the price index of other consumer goods. Income figures are taken from the Annual Report on Prefectural Accounts (Cabinet Office) and converted to real figures based on the total prefectural consumption deflator. Regarding household size and floor space, national census data and housing and land survey data published by Japan's Ministry of Internal Affairs and Communications are used. The ageing population data are taken from the Population Census (Statistics Bureau, Ministry of Internal Affairs and Communications). The data on heating and cooling degree days are obtained from The Energy Data and Modelling Center [35]. The annual number of cooling degree days is the cumulative difference of temperatures between $22{ }^{\circ} \mathrm{C}$ and the average temperature on each day in a year whose average temperature exceeds $24{ }^{\circ} \mathrm{C}$, while the annual number of heating degree days is the cumulative difference of temperatures between $14{ }^{\circ} \mathrm{C}$ and the average temperature on each day in an annual period whose average temperature is below $14{ }^{\circ} \mathrm{C}$.
Table 2 Estimation results

\begin{tabular}{|c|c|c|c|c|}
\hline & \multicolumn{2}{|l|}{ Model A } & \multicolumn{2}{|l|}{ Model B } \\
\hline & Coefficient & Standard error & Coefficient & Standard error \\
\hline Constant (a) & $-0.269^{a}$ & $(0.035)$ & $-0.401^{a}$ & $\overline{(0.037)}$ \\
\hline$a \mathrm{P}$ & $-0.651^{\mathrm{a}}$ & $(0.017)$ & $-0.618^{a}$ & $(0.020)$ \\
\hline$a \mid C$ & $0.397^{\mathrm{a}}$ & $(0.022)$ & $0.365^{\mathrm{a}}$ & $(0.022)$ \\
\hline aHS & $0.135^{\mathrm{b}}$ & $(0.067)$ & $0.150^{\mathrm{a}}$ & $(0.056)$ \\
\hline aFA & $0.328^{a}$ & $(0.072)$ & $0.303^{a}$ & $(0.061)$ \\
\hline$a A G$ & $0.171^{\mathrm{a}}$ & $(0.048)$ & $0.132^{\mathrm{a}}$ & $(0.044)$ \\
\hline aCDD & $0.180^{\mathrm{a}}$ & $(0.016)$ & $0.150^{\mathrm{a}}$ & $(0.015)$ \\
\hline$a \mathrm{HDD}$ & $-0.134^{\mathrm{a}}$ & $(0.019)$ & $-0.139^{a}$ & $(0.018)$ \\
\hline Constant $(\beta)$ & $-0.976^{b}$ & $(0.472)$ & -2.019 & (1.534) \\
\hline$\beta H S$ & $-1.034^{\mathrm{a}}$ & $(0.219)$ & $-0.213^{b}$ & $(0.097)$ \\
\hline$\beta F A$ & $1.171^{\mathrm{a}}$ & $(0.230)$ & $0.396^{\mathrm{a}}$ & $(0.101)$ \\
\hline$\beta A G$ & -0.022 & $(0.133)$ & -0.137 & $(0.084)$ \\
\hline Time dummies & No & & Yes & \\
\hline Sigma-squared & $0.382^{\mathrm{a}}$ & $(0.065)$ & $0.174^{\mathrm{a}}$ & $(0.015)$ \\
\hline Gamma & $0.770^{\mathrm{a}}$ & $(0.040)$ & $0.602^{a}$ & $(0.047)$ \\
\hline Log likelihood & -417.382 & & -344.568 & \\
\hline Mean efficiency & 0.770 & & 0.690 & \\
\hline
\end{tabular}

${ }^{a}$ Significance at the $1 \%$ level

${ }^{\mathrm{b}}$ Significance at the $5 \%$ level

Table 1 shows the descriptive statistics. For the estimations, the data were standardised by subtracting the average values from the original data and dividing it by the standard deviation.

\section{Results and discussion}

Table 2 shows the results of the estimates for the stochastic frontier demand function. Model A does not consider the time dummy in the error term, while model B does. Model $B$ is prepared in order to verify the robustness of the results. For both models, the signs of the estimated coefficients are as expected and all variables are statistically significant.

As it is a log-log variable, the estimated coefficient can be interpreted as elasticity. The estimated price elasticity is -0.651 and income elasticity 0.397 ; the price and income elasticities are larger compared with those in previous studies on Japanese residential electricity demand [36]. Since this study does not consider the lag of the electricity demand in estimating the power demand function,

Table 3 Energy efficiency scores

\begin{tabular}{lll}
\hline Summary measure & Model A & Model B \\
\hline Mean & 0.77 & 0.69 \\
Median & 0.82 & 0.71 \\
Max & 0.97 & 0.97 \\
Min & 0.16 & 0.14 \\
Std. dev. & 0.14 & 0.19 \\
\hline
\end{tabular}


Table 4 Average efficiency scores and rankings

\begin{tabular}{|c|c|c|c|c|}
\hline & Model A & & Model B & \\
\hline & Efficiency score & Rank & Efficiency score & Rank \\
\hline Hokkaido & 0.57 & 44 & 0.65 & 25 \\
\hline Aomori & 0.73 & 32 & 0.66 & 23 \\
\hline Iwate & 0.75 & 27 & 0.65 & 26 \\
\hline Miyagi & 0.83 & 15 & 0.72 & 14 \\
\hline Akita & 0.80 & 18 & 0.72 & 11 \\
\hline Yamagata & 0.78 & 22 & 0.63 & 30 \\
\hline Fukushima & 0.79 & 21 & 0.65 & 24 \\
\hline Ibaraki & 0.85 & 8 & 0.72 & 13 \\
\hline Tochigi & 0.84 & 11 & 0.70 & 17 \\
\hline Gunma & 0.76 & 24 & 0.62 & 32 \\
\hline Saitama & 0.89 & 2 & 0.79 & 5 \\
\hline Chiba & 0.88 & 3 & 0.80 & 4 \\
\hline Tokyo & 0.87 & 7 & 0.81 & 3 \\
\hline Kanagawa & 0.91 & 1 & 0.87 & 1 \\
\hline Niigata & 0.80 & 20 & 0.66 & 22 \\
\hline Toyama & 0.59 & 42 & 0.48 & 44 \\
\hline Ishikawa & 0.52 & 46 & 0.43 & 46 \\
\hline Fukui & 0.39 & 47 & 0.33 & 47 \\
\hline Yamanashi & 0.70 & 34 & 0.57 & 36 \\
\hline Nagano & 0.60 & 40 & 0.50 & 40 \\
\hline Gifu & 0.76 & 26 & 0.60 & 34 \\
\hline Shizuoka & 0.83 & 12 & 0.70 & 18 \\
\hline Aichi & 0.84 & 10 & 0.71 & 16 \\
\hline Mie & 0.75 & 29 & 0.63 & 31 \\
\hline Shiga & 0.65 & 37 & 0.50 & 41 \\
\hline Kyoto & 0.62 & 39 & 0.53 & 39 \\
\hline Osaka & 0.80 & 19 & 0.68 & 21 \\
\hline Hyogo & 0.82 & 16 & 0.71 & 15 \\
\hline Nara & 0.77 & 23 & 0.63 & 29 \\
\hline Wakayama & 0.52 & 45 & 0.46 & 45 \\
\hline Tottori & 0.59 & 43 & 0.50 & 43 \\
\hline Shimane & 0.63 & 38 & 0.55 & 37 \\
\hline Okayama & 0.65 & 36 & 0.55 & 38 \\
\hline Hiroshima & 0.73 & 31 & 0.64 & 27 \\
\hline Yamaguchi & 0.75 & 30 & 0.69 & 19 \\
\hline Tokushima & 0.59 & 41 & 0.50 & 42 \\
\hline Kagawa & 0.68 & 35 & 0.57 & 35 \\
\hline Ehime & 0.72 & 33 & 0.64 & 28 \\
\hline Kochi & 0.75 & 28 & 0.69 & 20 \\
\hline Fukuoka & 0.83 & 14 & 0.73 & 10 \\
\hline Saga & 0.76 & 25 & 0.62 & 33 \\
\hline Nagasaki & 0.83 & 13 & 0.75 & 9 \\
\hline Kumamoto & 0.87 & 6 & 0.78 & 6 \\
\hline
\end{tabular}

Table 4 Average efficiency scores and rankings (Continued)

\begin{tabular}{lllll}
\hline Oita & 0.81 & 17 & 0.72 & 12 \\
Miyazaki & 0.85 & 9 & 0.78 & 7 \\
Kagoshima & 0.88 & 4 & 0.84 & 2 \\
Okinawa & 0.87 & 5 & 0.76 & 8 \\
\hline
\end{tabular}

the estimated price and income elasticities mean longterm elasticity and, therefore, large values. As only the time dummy was considered in the estimates, there are no major differences in the sizes of estimated coefficients and the results are robust. The elasticity of household size is comparatively small, at 0.135 . This result suggests that, if household size increases by $10 \%$, electricity demand will also increase by about $1.35 \%$. The elasticity of household floor area is 0.328 , which is large compared to household size. The elasticity of the ageing population ratio is significant, at 0.171 . This factor's impact was relatively smaller than the economic factors' impacts, such as price and income. For the temperature variables, the cooling and heating degree days were both statistically significant but small. Therefore, it can be said that air temperature does not have a major impact on overall residential electricity demand. The coefficient of the heating degree day is negative, and this result is influenced by the higher usage rate for kerosene for electricity in heating demand in cold climate areas. For example, heating demand in Hokkaido uses more kerosene than electricity.

Subsequently, we confirm the estimation results for the coefficients $(\beta)$ of the variables that explain electricity efficiency. The signs of the household size variables $(\beta \mathrm{HS})$ and signs of floor area variables ( $\beta$ FA) are negative and positive, respectively, as expected. These results show that as household size increases, so does efficiency. The results also showed that as electricity efficiency improves, the smaller the floor area is. In both models A and B, the estimated coefficient of the floor area greatly exceeds the estimated coefficient of household size. This result signifies that the effects on efficiency of a decrease in residential floor area, which has occurred alongside the migration of people from local to agglomerated urban regions, are greater than the effects of household size. As there are many small detached houses and condominiums in urbanised cities, this result is consistent with those of previous studies, in that urbanised cities are energy efficient. The sign of the ageing population ratio ( $\beta A G)$ is negative but statistically insignificant. This result suggests that the ageing Japanese society does not influence electricity savings significantly. In other words, this result does not show the possibility of electricity savings with ageing.

Table 3 shows the average efficiency scores for the Japanese prefectures, obtained from the results of the estimates. An efficiency score of 1 represents the highest efficiency, and the lower the score, the lower the 
Table 5 Change rates (\%) of average scores over time

\begin{tabular}{|c|c|c|}
\hline & Model A & Model B \\
\hline Hokkaido & -0.61 & -1.83 \\
\hline Aomori & -0.83 & -2.57 \\
\hline Iwate & -2.01 & -3.86 \\
\hline Miyagi & -1.37 & -3.36 \\
\hline Akita & -2.21 & -3.79 \\
\hline Yamagata & -2.35 & -4.45 \\
\hline Fukushima & -1.46 & -3.64 \\
\hline Ibaraki & -0.76 & -2.57 \\
\hline Tochigi & -1.20 & -3.32 \\
\hline Gunma & -2.00 & -4.08 \\
\hline Saitama & -0.30 & -1.57 \\
\hline Chiba & -0.38 & -1.57 \\
\hline Tokyo & -0.33 & -1.46 \\
\hline Kanagawa & -0.14 & -0.81 \\
\hline Niigata & -1.88 & -4.05 \\
\hline Toyama & -5.75 & -7.05 \\
\hline Ishikawa & -5.78 & -7.24 \\
\hline Fukui & -7.10 & -8.64 \\
\hline Yamanashi & -1.80 & -3.91 \\
\hline Nagano & -3.33 & -4.97 \\
\hline Gifu & -2.36 & -4.42 \\
\hline Shizuoka & -1.46 & -3.51 \\
\hline Aichi & -0.93 & -2.84 \\
\hline Mie & -2.06 & -3.93 \\
\hline Shiga & -4.26 & -5.96 \\
\hline Kyoto & -2.82 & -4.64 \\
\hline Osaka & -0.94 & -2.95 \\
\hline Hyogo & -1.44 & -3.28 \\
\hline Nara & -2.56 & -4.37 \\
\hline Wakayama & -4.83 & -6.04 \\
\hline Tottori & -5.27 & -6.47 \\
\hline Shimane & -4.84 & -6.06 \\
\hline Okayama & -4.10 & -5.58 \\
\hline Hiroshima & -3.18 & -4.67 \\
\hline Yamaguchi & -3.55 & -4.65 \\
\hline Tokushima & -4.25 & -5.60 \\
\hline Kagawa & -3.65 & -5.17 \\
\hline Ehime & -2.85 & -4.32 \\
\hline Kochi & -2.42 & -3.72 \\
\hline Fukuoka & -0.98 & -2.88 \\
\hline Saga & -3.35 & -5.21 \\
\hline Nagasaki & -0.94 & -2.74 \\
\hline Kumamoto & -0.86 & -2.65 \\
\hline Oita & -1.68 & -3.44 \\
\hline
\end{tabular}

Table 5 Change rates (\%) of average scores over time (Continued)

\begin{tabular}{lll}
\hline Miyazaki & -1.11 & -2.74 \\
Kagoshima & -0.64 & -1.76 \\
Okinawa & -1.18 & -3.25 \\
\hline
\end{tabular}

energy efficiency level is. There are no major differences in the efficiency scores measured using models A or B. The average is 0.77 and the median 0.82 in model A. The largest score is 0.97 and the smallest 0.14 , which suggests that there are regional differences in electricity efficiency scores.

We now consider the regional distribution of the efficiency scores for residential electricity. Table 4 shows each prefecture's average efficiency scores and rankings. No major differences in rankings were seen between the results for models $\mathrm{A}$ and $\mathrm{B}$. The high-ranking regions included Kanagawa, Saitama, Chiba, and Tokyo, which are all large metropolitan areas where population has agglomerated. In contrast, Fukui had the worst efficiency, and the Hokuriku regions, including Ishikawa and Toyama, also had poor efficiency.

In Kanagawa, Saitama, Chiba, and Tokyo, the population is concentrated into densely inhabited districts and people live in multi-dwelling houses, which have a limited floor area and, consequently, higher electricity efficiency. Additionally, these prefectures have many singledwelling households with small overall household size. This tendency signifies electricity efficiency deteriorates because of the numerous household appliances per household member. According to the estimation results (Table 2), the parameter of the housing floor area ( $\beta$ FA) exceeds that of household size $(\beta \mathrm{HS})$, which suggests a stronger impact of the floor area. In other words, the results suggest that electricity efficiency is higher in Kanagawa, Saitama, Chiba, and Tokyo owing to the floor area. Otsuka and Goto $[26,27]$ verify that the impact of population density on energy efficiency is high in these regions. As in areas with high population density, there are more multi-dwelling houses, such as condominiums and apartments, than detached houses, our results are consistent with their findings. On the other hand, in Toyama, Ishikawa, and Fukui, there are many detached houses, which have larger residential floor areas than multi-dwelling houses. Therefore, energy waste is relatively higher in these regions.

Table 5 shows the average scores for electricity efficiency in the 1990s and 2000s. The results show two main findings. First, in regions with high energy efficiency, changes to the average scores were not observed. In other words, regions where energy efficiency is already high simply maintain these levels. Second, in low energy efficiency regions, the average scores worsened from the 1990s to the 
2000s, indicating their efficiency did not improve. Therefore, the results suggest that, in Japan, low energy efficiency regions are not catching up with the high energy efficiency ones, and through these increasing disparities, nationwide energy efficiency is deteriorating.

Figure 1 shows the relationships between the regions' detached house shares in 2013 and the change rates of the energy efficiency scores. Overall, a downward sloping relationship can be seen. There are many detached houses in regions where regional efficiency scores deteriorated. In other words, this figure suggests that the increasing number of detached houses within residential areas may be causing electricity wastage.

\section{Conclusions}

This study measured the energy efficiency levels of residential electricity demand by analysing data on Japan's 47 prefectures, using a combination of electricity demand and stochastic frontier models. To the best of our knowledge, this study is the first to measure efficiency levels for residential electricity in Japan's prefectures. For the specification of electricity demand, price and income, household size, floor area, ageing, and climate were respectively controlled for to derive electricity energy efficiency. The efficiency level tends to depend on the economic and social structures of the region, whose influences were controlled for when deriving the efficiency scores, thus resulting in a more accurate index.
The results of our analysis confirm the importance of household dwelling types for the electricity energy efficiency. The findings suggest that household size and floor area are key to electricity savings. Going beyond the nuclear family and increasing the number of household members, the possibility of sharing home appliances increases. Large families may have many household electrical appliances and higher electricity consumption, but the number of kitchen appliances and the hot water supply should be constant. In this case, household appliance usage per household member decreases and, thus, per-capita electricity consumption may decrease (household scale economies). Furthermore, by living in a multi-dwelling house with a small floor area, energy intensity can improve, which means the energy efficiency level will be high. There are more multi-dwelling houses in cities than rural areas, and thus, the potential for energy efficiency improvement is high in cities. Therefore, promoting living in urban areas will result in electricity savings.

In conclusion, promoting living in urban areas by forming urbanised cities in each region would seem to be an effective strategy for increasing electricity energy efficiency. This policy is known to increase the productivity of regional economies through agglomeration economies, as well as environmental efficiency [2,37]. The results of our analysis show that, to achieve both higher productivity and energy efficiency, promoting residence

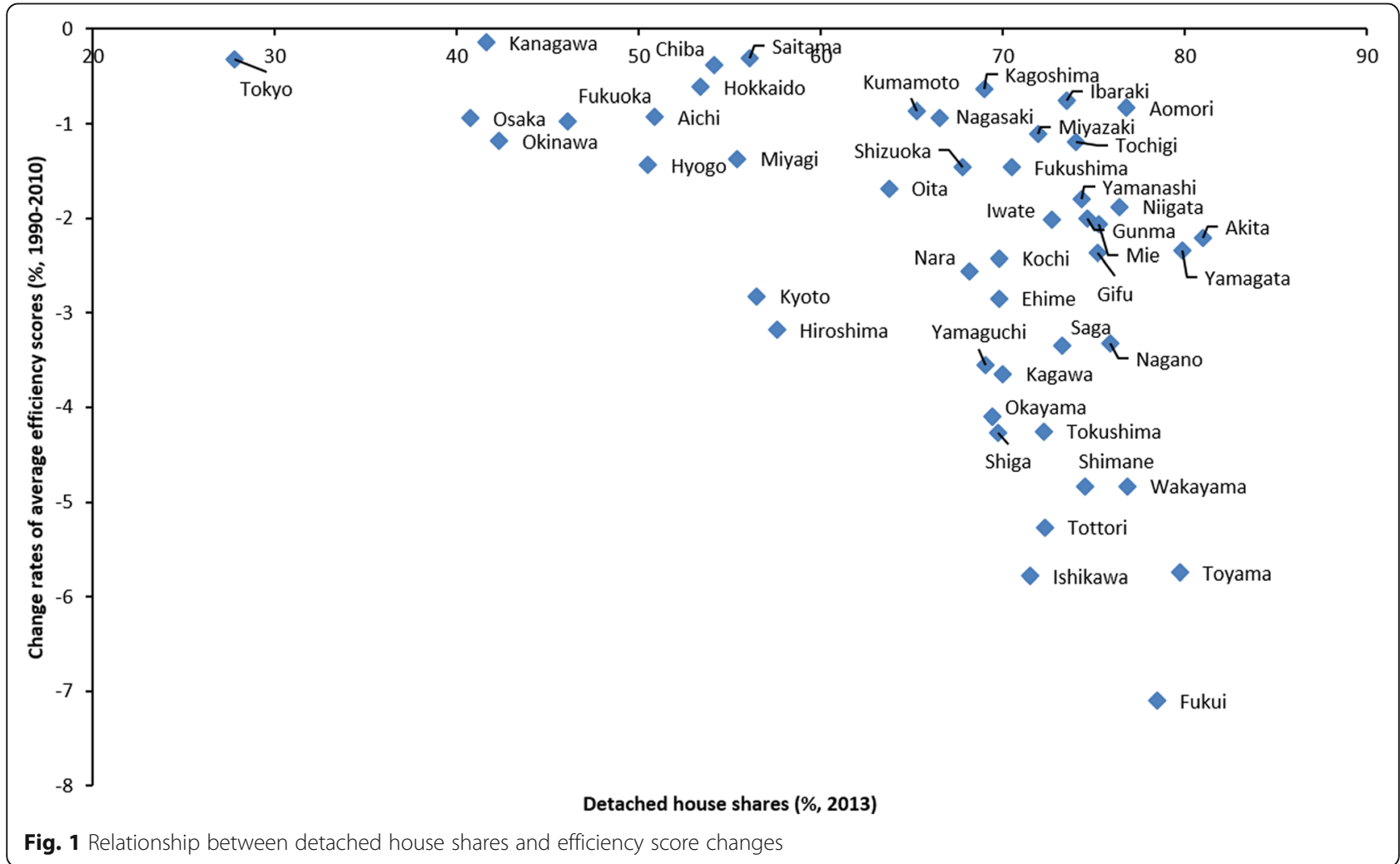


in areas where the population has agglomerated and forming multi-polarisation-type national spatial developments is vital. In Japan, a policy on constructing compact cities within local areas to increase population concentration is being discussed. Consequently, the impact of such a policy on the relationship between household dwelling types and energy consumption should be investigated in further studies.

\section{Endnotes}

${ }^{1}$ Lin and Wang [18] consider two factors-industry concentration and ownership structure-as the determinants of energy efficiency levels.

${ }^{2}$ More advanced SFA models are proposed by Colombi et al. [38], Kumbhakar et al. [39], Tsionas and Kumbhakar [40], and Filippini and Greene [41]. For example, the model proposed by Colombi et al. [38] can distinguish between short- and long-run efficiency levels. However, with such a model, we cannot analyse the determinants of the efficiency levels in a single-stage procedure.

${ }^{3}$ This study is unable to consider the stock of household appliances owing to data limitations. Thus, we instead assume that the stock of household appliances is proportional to household size, and the influence of the stock of home appliances is explained by household size. However, we must be cautious about assuming that this relationship is implicit.

\section{Funding}

This study was funded by the Japan Society for the Promotion of Science (grant no. 15K17067). Additionally, I have received a Grant-in-Aid for Young Scientific Researchers by Yokohama City University.

\section{Authors' contributions}

The author conducted the analysis and drafted the manuscript for the study. The author read and approved the final manuscript.

\begin{abstract}
Authors' information
Dr. Otsuka is an associate professor at Yokohama City University's Association of International Arts and Science, Japan. His field of expertise is empirical research on urban economics, regional economics, and energy economics. His representative papers were awarded the Martin Beckmann RSAI Annual Award and the RSPP Annual Paper Award. He is currently conducting research on sustainable regional economic systems through empirical studies on the economies of agglomeration and energy efficiency in regional economies.
\end{abstract}

\section{Competing interests}

The author declares that they have no competing interests.

\section{Publisher's Note}

Springer Nature remains neutral with regard to jurisdictional claims in published maps and institutional affiliations.

Received: 4 May 2017 Accepted: 15 September 2017

Published online: 09 October 2017

\section{References}

1. Ministry of Economy, Trade and Industry (2015) 2015 annual report on energy. Tokyo Research Institute of Economy, Trade and Industry, Tokyo

2. Otsuka A (2017) Regional energy demand and energy efficiency in Japan. Springer International Publishing, Cham
3. EIA (1995) Measuring energy efficiency in the United States' economy: a beginning. Energy Information Administration, DOE/EIA-0555(95)/2, Washington, DC, USA

4. EIA (2013) International energy outlook 2013. Energy Information Administration, U.S.

5. IEA (2009) Progress with implementing energy efficiency policies in the G8. International Energy Agency Paper

6. Murillo-Zamorano LR (2004) Economic efficiency and frontier techniques. J Econ Surv 18(1):33-77

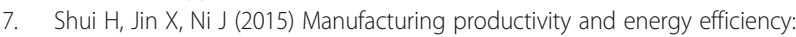
a stochastic efficiency frontier analysis. Int J Energy Res 39(12):1649-1663

8. Filippini M, Hunt LC (2015) Measurement of energy efficiency based on economic foundations. Energy Econ 52(Supplement 1):S5-S16

9. Zhou P, Ang BW, Zhou DQ (2012) Measuring economy-wide energy efficiency performance: a parametric frontier approach. Appl Energy 90(1):196-200

10. Feijoo ML, Franco JF, Hernández JM (2002) Global warming and the energy efficiency of Spanish industry. Energy Econ 24:405-423

11. Buck J, Young D (2007) The potential for energy efficiency gains in the Canadian commercial building sector. Energy 32:1769-1780

12. Boyd GA (2008) Estimating plant level energy efficiency with a stochastic frontier. Energy J 29:23-43

13. Boyd G, Dutrow E, Tunnessen W (2008) The evolution of the ENERGY STAR ${ }^{\oplus}$ energy performance indicator for benchmarking industrial plant manufacturing energy use. J Clean Prod 16:709-715

14. Aranda-Uson A, Ferreira G, Mainar-Toledo MD, Scarpellini S, Liera E (2012) Energy consumption analysis of Spanish food and drink, textile, chemical and non-metallic mineral products sectors. Energy 42:477-485

15. Filippini M, Hunt LC (2011) Energy demand and energy efficiency in the OECD countries: a stochastic demand frontier approach. Energy J 32:59-79

16. Filippini M, Hunt LC (2012) U.S. residential energy demand and energy efficiency: a stochastic demand frontier approach. Energy Econ 34:1484-1491

17. Lin BQ, Yang LS (2013) The potential estimation and factor analysis of China's energy conservation on thermal power industry. Energy Policy 62: 354-362

18. Lin B, Wang X (2014) Exploring energy efficiency in China's iron and steel industry: a stochastic frontier approach. Energy Policy 72:87-96

19. Filippini M, Lin B (2016) Estimation of the energy efficiency in Chinese provinces. Energy Effic 9(6):1315-1328

20. Newman PWG, Kenworthy JR (1989) Gasoline consumption and cities. J Am Plan Assoc 55(1):24-37

21. Bento AM, Cropper ML (2005) The effects of urban spatial structure on travel demand in the United States. Rev Econ Stat 87(3):466-478

22. Brownstine D, Golob TF (2009) The impact of residential density on vehicle usage and energy consumption. J Urban Econ 65(1):91-98

23. Karathodorou N, Graham DJ, Noland RB (2010) Estimating the effect of urban density on fuel demand. Energy Econ 32(1):86-92

24. Su Q (2011) The effect of population density, road network density, and congestion on household gasoline consumption in U.S. urban areas. Energy Econ 33(3):445-452

25. Morikawa M (2012) Population density and efficiency in energy consumption: an empirical analysis of service establishments. Energy Econ 34:1617-1622

26. Otsuka A, Goto M (2015) Estimation and determinants of energy efficiency in Japanese regional economies. Reg Sci Policy Pract 7(2):89-101

27. Otsuka A, Goto M (2017) Regional determinants of energy intensity in Japan: the impact of population density. Asia-Pac J Reg Sci, July 2017, DOI: https://doi.org/10.1007/s41685-017-0045-1

28. Meeusen W, van den Broeck J (1977) Efficient estimation from Cobb-Douglas production functions with composed error. Int Econ Rev 18(2):435-444

29. Aigner DJ, Lovell CAK, Schmidt P (1977) Formulation and estimation of stochastic frontier production function model. J Econom 6:21-37

30. Battese GE, Corra GS (1977) Estimation of a production frontier model: with application to the pastoral zone of eastern Australia. Aust J Agric Econ 21(3): 169-179

31. Kumbhakar SC, Lovell CAK (2000) Stochastic frontier analysis. Cambridge University Press, Cambridge

32. Battese GE, Coelli TJ (1995) Model for technical inefficiency effects in a stochastic frontier production function for panel data. Empir Econ 20(2):325-332

33. Jondrow J, Knox Lovell CA, Materov IS, Schmidt P (1982) On the estimation of technical inefficiency in the stochastic frontier production function model. J Econom 19(2):233-238 
34. Flaig G (1990) Household production and the short- and long-run demand for electricity. Energy Econ 12(2):116-121

35. EDMC (2016). EDMC Handbook of Japan's \& World Energy \& Economic Statistics 2016. Energy Conservation Center, Tokyo

36. Otsuka A, Haruna S (2016) Determinants of residential electricity demand: evidence from Japan. Int J Energy Sect Manag 10(4):546-560

37. Otsuka A, Goto M, Sueyoshi T (2014) Energy efficiency and agglomeration economies: the case of Japanese manufacturing industries. Reg Sci Policy Pract 6(2):195-212

38. Colombi R, Kumbhakar SC, Martini G, Vittadini G (2014) Closed-skew normality in stochastic frontiers with individual effects and long/short-run efficiency. J Product Anal 42(2):123-136

39. Kumbhakar SC, Lien G, Hardaker JB (2014) Technical efficiency in competing panel data models: a study of Norwegian grain farming. J Product Anal 41(2):321-337

40. Tsionas EG, Kumbhakar SC (2014) Firm heterogeneity, persistent and transient technical inefficiency: a generalized true random-effects model. J Appl Econ 29(1):110-132

41. Filippini M, Greene W (2016) Persistent and transient productive inefficiency: a maximum simulated likelihood approach. J Product Anal 45(2):187-196

\section{Submit your manuscript to a SpringerOpen ${ }^{\circ}$ journal and benefit from:}

- Convenient online submission

- Rigorous peer review

- Open access: articles freely available online

- High visibility within the field

- Retaining the copyright to your article

Submit your next manuscript at $\boldsymbol{s p r i n g e r o p e n . c o m ~}$ 